\title{
La fortificación de la monarquía de Felipe II *
}

\author{
alicia Cámara muñoz
}

Dijo Don Quijote: “Bien hayan aquellos benditos siglos que carecieron de la espantable furia de aquestos endemoniados instrumentos de la artilleria, a cuyo inventor tengo para mí que en el infierno se le está dando el premio de su diabólica invención". Estuviera o no en el infierno su inventor, el hecho es que las nuevas armas transformaron el arte de la guerra en el Renacimiento tanto en cuanto al ataque como a la defensa. Unas mismas armas obligaron a un tipo de defensa único que debió ir adaptándose a la evolución de las formas de ataque. Si a ello añadimos que las fortalezas del siglo xvi fueron construidas por los monarcas para defender sus reinos, puertos y ciudades, y no por los nobles con intereses particulares, dándose incluso prohibiciones en ese sentido, encontramos que el Renacimiento supuso un cambio radical con respecto al sistema de fortificación medieval, que no se puede centrar únicamente en la aparición y consolidación del baluarte.

\section{LA FORTIFICACIÓN DE LOS REINOS DE LA MONARQUÍA}

En lo que a la monarquia española se refiere, todas las actuaciones en materia de fortificación se centralizaron de manera clara en el reinado

* Este artículo, ligeramente modificado y ampliado es parte de una ponencia presentada en el Congreso Internacional sobre "Fronteras en Iberoamérica. Ayer y Hoy", celebrado en Tijuana (México) del 23 al 25 de agosto de 1989. 
de Felipe II: el Consejo de Guerra, de quien dependía la guerra de tierra y mar, se ocupará de las obras, aunque sea el Consejo de Indias el que se ocupe más directamente de las fortalezas americanas; un militar fue destinado a cada zona para ocuparse de las obras, acompañado siempre por un ingeniero, y así nos encontramos al capitán general Vespasiano Gonzaga («más inteligente que ninguno en la fortificación» según Bautista Antonelli) visitando e informando por ejemplo de las fortificaciones de la costa levantina, de Navarra o del norte de Africa, acompañado unas veces por J. B. Antonelli y otras por Fratin, y en América también un militar - el maese de campo Juan de Tejada - fue el responsable de las fortificaciones del Caribe e istmo de Panamá en última instancia, aunque el ingeniero Bautista Antonelli fuera el técnico, el profesional que dictaminaba. El control de todo lo que en materia de fortificación se hizo en las fronteras de la monarquía se llevaba en la corte, y con el tiempo se creó la figura del ingeniero mayor, por cuyas manos habian de pasar todas las trazas para ser informadas y dar su parecer. Todo ello se tradujo en una paulatina normalización o codificación en cuanto a materiales, tipologías, oficios en las obras, instrucciones, etc...

La geografía de la península facilitaba su defensa, con los montes Pirineos en la frontera con Francia, y el mar rodeando los reinos peninsulares. Fortificados también los reinos de la monarquía en Italia para la defensa de los turcos, la monarquía española fue cerrando sus territorios con un sistema de fortalezas: si a lo largo del siglo Xvı fuéramos visualizando en un mapa de la península las intervenciones en materia de fortificación, encontrariamos que siguen una evolución en sentido inverso a las agujas de un reloj, con la excepción de las fortificaciones en la frontera con Francia, que siempre fueron prioritarias. Así, el sur y la costa norte de África en primer lugar, más adelante las islas Baleares y Cataluña y luego, sobre todo en la década de los setenta, toda la costa levantina, nos van mostrando con sus fortificaciones la evolución de los temores de la monarquía. En cambio la costa atlántica estuvo menos fortificada durante un tiempo, ya que el mar era más bravío, la misma costa era por si misma más fuerte y sobre todo - según J. B. Antonellihabía "pocos enemigos y no muy poderosos por aquella parte" '. Por aquella parte lo que se fortificaría sería la carrera de Indias hasta la nueva frontera del otro lado del mar, guardada también con fortificaciones.

Los textos que se citan de Juan Bautista Antonelli están tomados de dos memoriales de este ingeniero que se conservan en el Archivo General de Simancas, Guerra Antigua, leg. 72, f. 294 y 295. 
La España del Renacimiento se fue pareciendo cada vez más a lo que Platón exponía en Las Leyes cuando decía que después de haber fortificado las fronteras del Estado para impedir el paso al enemigo, sería motivo de risa cerrar las ciudades con murallas; en España en efecto se fortificaron las fronteras, y las actuaciones en las murallas de las ciudades se limitaron a la construcción de puertas o incluso de muros, pero sin función defensiva (salvo en casos concretos como puedan ser Cádiz, La Coruña, u otras ciudades costeras por su ubicación geográfica), sino como límite de la vida urbana.

El tema de la defensa de las fronteras de los reinos con fortalezas tuvo al parecer también sus criticos, y hubo partidarios de que quien tuviera muchos lugares de frontera (como le pasaba a España) los guardara "con un exercito en campaña» y no se pusiera "a presidiarlos todos", pero la lentitud de movimientos de un ejército aconsejó lo segundo.

Las connotaciones actuales que tiene la palabra "presidio" hace que sea buena quizá una aclaración sobre su uso en el xvI: la utilización del verbo "presidiar" en lugar de "fortificar" lo encontramos no sólo en Juan Bautista Antonelli, a quien pertenecen las palabras anteriores, sino también en la Relación de España que daba el embajador veneciano Leonardo Donato, en 1573, cuando hablaba de que la costa española de Levante "se vería obligada a presidiarse" ante una posible amenaza desde Berbería. La diferencia entre las palabras fortaleza y presidio está clara, una se refiere a la arquitectura militar y la otra a la guarnición que hay en ella, aunque por extensión se llame presidio a veces a toda fortaleza con una guarnición de soldados. Tanto Nebrija en su Diccionario latino español de 1492 ("Preses. idis. alcaide o capitán de guarnición. Presidium. ii. por aquella guarnición"), como Covarrubias en el Tesoro de la Lengua Castellana de 1611 ("comúnmente llamamos presidio al castillo o fuerça donde ay gente de guarnición») dejan claro el por qué del uso de este término para algunas fortificaciones fronterizas, aunque es frecuente que la palabra se emplee con propiedad, para referirse sólo a la guarnición.

Los presidios fueron característicos de las fronteras españolas, y es un término usado con más frecuencia para las fortalezas del norte de Africa y de América que para otras zonas; fronteras ambas al otro lado de un mar que casi se consideraba también propio, los presidios habitados por los soldados fueron como fuertes barcos solitarios anclados en sus costas, y tan dependientes de los socorros exteriores como un barco en la mar según decía Vespasiano Gonzaga. En los presidios vivian esos soldados españoles que alababa Maquiavelo ( $\mathrm{Del}$ arte de la guerra, 1521) «porque como luchan en territorio extranjero y se ven obligados a 
vencer o a morir, por no tener retirada posible, se han hecho buenos soldados".

Sobre el carácter de frontera de la monarquía que tuvieron esas costas lejanas hoy no nos cabe duda, pero también así fueron vistas por los contemporáneos. Con respecto a Berbería el mismo embajador Donato afirmaba que él la llamaba «frontera de España, como de cosa que pertenece a la defensa de esta provincia y es propia de este lugar». A este respecto, y por las mismas fechas, Juan Bautista Antonelli ponía en boca de Fernando el Católico palabras que hacían referencia a la condición de frontera que tenía lo que "havia ganado en Berbería".

La identificación entre frontera y fortaleza fue clara: el mismo Antonelli, en un memorial sobre la defensa de la frontera con Francia, se refiere en la parte de Navarra a los mejores lugares upara hazer frontera al enemigo", cuando habla de lugares en los que sería bueno construir "fuerzas». Este ingeniero en sus escritos identifica "hacer frontera" con fortificar, y si no se fortifica, se tienen las "fronteras abiertas".

Con respecto a América, la idea de frontera con un tipo de asentamiento militar podemos pensar que trasciende incluso el mismo tema de las fortalezas, al utilizarse para la colonización asentamientos urbanos que pueden recordar lo que Maquiavelo decía de los campamentos militares, "que a donde quiera que va lleva siempre las mismas calles, las mismas casas y el mismo aspecto", y el famoso trazado de las ciudades americanas que hunde sus orígenes en la antigüedad, fue utilizado por los ingenieros militares de Felipe II como instrumento de colonización en lugares tan distantes como Carlentini en Sicilia o La Habana en Cuba a pesar de que el trazado favorito de los tratadistas militares para una ciudad o ciudadela fuera el trazado radial, tanto en la tratadística italiana como en la española del siglo xvI.

En todo el sistema de fortificación costero, las grandes obras se emprendieron en los puertos: si se pensó abandonar Melilla entre otras razones por carecer de puerto, el puerto de Cartagena en España fue siempre famoso y se procuró una buena fortificación para él, y en América todas las grandes fortalezas del XVI (aunque también hubo fortalezas interiores para defenderse de los indígenas) se construyeron para defensa de los puertos. Al fin y al cabo, lo mismo que en los Pirineos fueron los lugares de paso los defendidos con fuertes, en las costas lo fueron los lugares de desembarco. El sistema defensivo de las fortalezas justificaba la necesidad de las salvas al entrar en puerto, código perfectamente 
establecido por ley para identificar al barco amigo que entraba, barco que quedaba guardado a partir de ese momento por dicha fortaleza.

\section{EL PENSAMIENTO SOBRE LA FORTIFICACIÓN}

Las murallas, ciudadelas, presidios y fortalezas llevadas a cabo en el siglo XVI siempre marcaron una frontera: frontera urbana en el caso de las ciudades, frontera del poder real que controla una ciudad en el caso de las ciudadelas, frontera económica en el caso de la navegación y puertos de las Indias, frontera política y religiosa en el Mediterráneo... y siempre tienen un "dentro" de seguridades frente a un "fuera" del que sólo cabe esperar la agresión. Creo que son muestra de un pensamiento político acerca de la guerra y la defensa que aunque dominó en Europa, tuvo en España su mejor ejemplo.

Antes de pasar a hablar de ello merece la pena recordar que para esta monarquía católica, las fortificaciones fueron investidas de una concreta simbologia religiosa. Ya los castillos a la antigua, con torreones redondos (inútiles ante las nuevas armas) y con una torre en el centro («de cuando se combatía con piedras" como dice González de Medina Barba en 1598), como eran algunos de los Pirineos, reformados algo en tiempo de Felipe II, estuvieron cargados de simbolismo. El tema del castillo asociado a la religión católica es reiterativo, y si la cruz de Cristo puede aparecer en un romance de Ledesma (1600), como un "fortissimo castillo", y el amor de la Virgen en 1610 como "muro inexpugnable", en un sermón del año 1611 se dirá que las iglesias han de ser llamadas fortalezas y casas de munición, y abunda en esa imagen un sermón del año 1656 en México en el que la catedral de esa ciudad es aludida como "defensa, baluarte, y presidio". El tema del castillo, baluarte, etc., fue, como vemos, asociado a la religión católica durante todo el Barroco.

En la práctica, la frontera religiosa que supusieron también las fortificaciones, se puso de manifiesto en las advocaciones de los castillos y, en los casos de grandes fortalezas o ciudades fortificadas, en los nombres dados a los baluartes. Durante el reinado del emperador Carlos, los baluartes recibian nombres a veces como "baluarte del gobernador", "cubo de Leiva»..., pero en el reinado de su hijo esa costumbre (aunque conservada parcialmente dando por ejemplo a veces el nombre del ingeniero a un baluarte, $y$ aunque los nombres de los grandes generales 
permanezcan unidos a las fortificaciones a través de escudos e inscripciones) casi va a desaparecer pues la función que tuvieron las fortalezas dentro de la concepción que de la monarquía tuvo este rey, y de una mentalidad claramente contrarreformista, hizo que la protección de los santos, ante unos enemigos que además profesaban religiones distintas, bautizara las fortalezas. Así, se van a repetir los nombres de San Felipe (el santo del rey) y sobre todo de santos que fueron militares: San Sebastián, San Jorge, San Lázaro...; de santos cuya fortaleza se manifestó ante el martirio como San Juan y San Andrés; de santos valerosos en la lucha contra los demonios, como San Antonio; del santo patrono de España Santiago -en España "matamoros", en América «mataindios»- y también de santas, vírgenes y fuertes ante el martirio - Santa Lucía, Santa Bárbara, Santa Catalina- además de sabias y capaces de argumentar y discutir cientificamente acerca de la fe cristiana como en el caso de Santa Bárbara y Santa Catalina. Como se ve no valía cualquier santo, y en la elección de los nombres hay explícitos mensajes contrarreformistas de la fe católica.

Por lo que se refiere a la idea del imperio que justificó la construcción de fortalezas en todas las fronteras, debemos recordar que el pensamiento de que aquel que quiere la paz ha de estar preparado para la guerra subyace más o menos explícito en todos los escritores políticos. Por lo que se refiere a las fortificaciones, Maquiavelo en El Príncipe se refirió a las fortalezas como la "brida y freno" que los príncipes ponian ante los enemigos desde la antigüedad, y el ingeniero Marchi en su tratado sobre arquitectura militar hablaba de la gratitud que el pueblo debia sentir hacia los príncipes que fortificaban ciudades y tierras por la seguridad que ello daba.

Juan Bautista Antonelli afirmará en un memorial a Felipe II sobre la defensa del Imperio, que todo reino que dura es necesario que ofenda y sea ofendido, diciendo que no habla "agora de tiempos cortos, sino de los con que se ha de considerar las Vidas de los Imperios". La necesidad de la guerra, "seguridad y defensa del reyno y de la paz" según Mateo López Bravo (Del Rey y de la raçon de governar, 1616), hace decir al mismo autor que "es necesario que el que manda resulte odioso a los que son mandados", pues "siempre nacieron juntos el odio y el imperio". Y en la Politica para Corregidores de Castillo de Bobadilla se dice que ninguna nación como la española tiene más necesidad de «murallas, castillos y plazas fuertes" por el odio que despierta su gran Imperio.

Las fortificaciones, como ya hemos dicho, cerraron los reinos de la monarquía, protegiendo el centro, esos reinos peninsulares cuyo corazón 
a su vez era Madrid, desde donde Felipe II "tiraba con admirable providencia, y rectitud las líneas del gobierno a la circunferencia de su amplísima corona". En este sentido decía Antonelli en el Memorial citado, que se equivocaban los que decian que España estaría mejor sola, sin Flandes y sin Italia, porque el día que España no tuviera "frontera a sus enemigos en aquellas partes", así como en Berbería, en los Pirineos y en las costas del Mediterráneo y del Océano, las heridas de esos enemigos las recibiría en el corazón.

El sistema de fortificación de las fronteras dio unidad a una monarquia que abarcaba extensos territorios en distintos continentes. La idea de unidad defendida por los escritores políticos es clara: a fines del XVI afirmaba G. López Madera, en las Excelencias de la monarchia y Reyno de España, que el reino de España era sólo uno aunque estuviera dividido en muchos títulos, y que no tenía superior en lo temporal.

Sancho de Moncada, por su parte, en 1619 (Restauración politica de España) mostraba su desacuerdo con los que opinaban que la decadencia de España se debía a la extensión de sus territorios, pues según él "el sitio de España pide forzosamente gran parte de otras conquistas, porque mira a África, y ha menester asegurar sus costas", y "en Indias se han hecho colonias, que son de Españoles, que pueden socorrer en aprietos». También Fr. Juan de Salazar (Política española, 1619) dirá que a pesar de que había quienes pensaban que la monarquía española no podía ser duradera por estar "sus reinos y estados desunidos y apartados", sin embargo esta monarquía gracias a la navegación señoreaba los mares y mantenía unidos sus estados; además, dice que gracias a la unión que existe entre los cuerpos (los matrimonios), las haciendas (el comercio) y los entendimientos (la religión católica) los vasallos están tan unidos como si estuvieran todos dentro de Castilla la Vieja.

La idea de que todo es uno, y lo más grande en lo temporal, así como que con ello se despierta un odio inevitable en otras naciones, justificó las enormes cantidades de dinero y de hombres (desde los ingenieros hasta el último soldado) que se emplearon en la defensa de las fronteras europeas, africanas y americanas. Todas esas fortificaciones contribuyeron según los historiadores a la gloria y la fama de Felipe II, y así, cuando Vander Hammen hizo su elogio de Felipe II, todas las fortificaciones que mandó hacer en sus reinos fueron reseñadas una por una. Cuando Fr. Juan de Salazar en 1619 se refiera al «imperio y señorío que tiene España en el mundo", las fortalezas que tiene esta monarquía en los distintos continentes también van a ser enumeradas, y parece que en gran medida identifica las fortalezas con el control de un territorio. De hecho dice que la monarquía consiste en reinos, provincias, islas, "forta- 
lezas», puertos y diversos estados, siendo además señora absoluta del Océano Atlántico, «por ser suya casi toda la costa y por potencia y gran número de navíos de alto bordo, galeones, galeras y otros bajeles", siendo los galeones "otros tantos castillos roqueros dentro del mar". De nuevo el tema de la navegación como elemento de cohesión de los reinos nos permite comprender la imagen de unidad que se pretendía dar de una monarquía que fortificó rutas terrestres y navales, así como todos aquellos lugares en que "hizo frontera".

Las fortificaciones de la frontera, con sus puertas que se repiten, con sus escudos y armas, con sus reglamentos sobre cargos y oficios, con sus tipologías defensivas adaptadas a las nuevas armas, no lograron realmente cerrar el imperio, y ahí está por ejemplo el contrabando lo mismo en los Pirineos que en América para demostrarlo, pero sí crearon, con una arquitectura específica de la frontera, un lenguaje de dominio que se pretendió tan universal como la monarquia católica. 